\title{
20
}

\section{IDENTIFYING THE MAIN CONSTRUCTS FOR AN INTERDISCIPLINARY WORKPLACE MANAGEMENT FRAMEWORK}

\author{
Vitalija Danivska*, Rianne Appel-Meulenbroek \\ and Susanne Colenberg
}

\section{Introduction}

The 18 theories covered in this book have addressed various workplace management issues. Some focused on explaining the overall organisational systems, relationships between system components, and the position of workplace management within such systems (e.g. the St. Gallen Management Model, see Chapter 4). Others have explained the necessary workplace management processes and their effects on employees and the organisation as a whole (e.g. workplace branding, see Chapter 11; hospitality, see Chapter 17). But despite their differences in focus, all these theories emphasise that alignment between an organisation and its workplace management is critical to add strategic value for the various stakeholders. Several studies describe stakeholders that are relevant to (physical) workplace management (e.g. Coenen et al., 2013; Blakstad et al., 2008). Tagliaro (2018) summed up the key stakeholders as: executives, employees, collaborators, visitors, owners, and those in charge of building operations. Each of them has different interests that need to be addressed by aligning the workplace to the organisation.

The topic of alignment is not new in the organisational management context. For example, in organisational studies, it has been identified that strategy, structure, rewards, processes, and environments need to be aligned (Galbraith, 2014). Alignment has also been studied in the context of workplace management, both from the viewpoint of the corporate real estate portfolio (see, e.g. Heywood \& Arkesteijn, 2017; also Chapter 9) and that of human resource management strategies and activities (see, e.g., Huselid \& Becker, 1997; Gagné, 2018). However, there is more to workplace alignment than aligning the corporate real estate strategy to the corporate strategy at the strategic level, which so far seems to be the focus of such studies. Organisations are complex systems made of relations between the physical and the social (Becker, 1981). Already in 1973, Steele introduced this notion with the term 'organisational

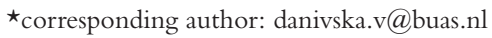


space', referring to the idea that the spatial environment influences people in and around the organisation. More recently, Luhman and Cunliffe (2013) defined organisational space as "built environments and the objects and social practices within them" (p. 135). Some even say that organisational space should be understood as physical, mental, and social space going beyond organisational limits (Tissen \& Lekanne Deprez, 2008). However, so far organisational space research often approaches physical space as a secondary factor without measuring its effects, and the organisational space concept is seldom the focus of built environment studies. Similarly, in practice many corporate real estate and facilities managers still treat workplace as nothing more than just a physical space (Alexander \& Price, 2012), not always paying enough attention to the social or mental aspects.

The previous chapters in this book have addressed many aspects that must be included in workplace alignment related to organisational systems and their components (see Chapters 4 and 5), the relationships between organisational units (see Chapter 10), and the processes within organisational management (see Chapter 7). In addition, workplace management tasks (see Chapters 2, 6, 11, and 15) and processes (see Chapters 12, 13, and 16) are widely covered too. So, a lot of theoretical knowledge has been discussed that could support stakeholder and goaloriented design of organisational management processes towards improved, more holistic and aligned workplace management. Organisational space, the workplace, clearly requires a holistic treatment of all dimensions (physical, social, and mental). Therefore, scientific insights related to workplace management must be gathered from across different fields and different theories. This book has been an attempt to bring some of these theories and insights together, with this chapter taking a first step towards integrating them into an overall framework. This framework, hopefully, is a first step towards developing a grand Workplace Management theory in future studies.

\subsection{A Workplace Management theory}

Workplace and workplace management have been defined in the introductory chapter of this book (see Chapter 1). Likewise, Chapter 1 explains that theory can be defined as "a statement of concepts and their interrelationships that shows how/or why a phenomenon occurs" (Corley \& Gioia, 2011, p. 12). As workplace by itself requires interdisciplinary understanding, it obviously calls for an interdisciplinary approach to the identification of such concepts, which must be followed by a transdisciplinary approach for testing interrelationships under different conditions. Here we introduce the first step towards the development of a new, grand Workplace Management theory by identifying the focal concepts across all theories presented in this book (see Table 20.1). As these theories stem from a variety of disciplines, the result automatically is an interdisciplinary framework. In its first set-up, the book was supposed to include another theory on performance-based buildings, focused on what a building is required to do rather than how it should be constructed. Although the chapter was withdrawn later in the process, the theory remained part of the analysis for this framework as it had already been performed, and the theory is just as relevant to the field as the others in the book.

To create the framework, the most important tacit knowledge from the theories has been made explicit to capture the essence of each theory. This was followed by the identification of communalities between theories and creation of focal constructs, which then were used to connect the theories into said framework. The next section will explain the empirical approach (a concept mapping study) in greater detail, followed by the results, a discussion of the implications of findings for workplace research and practice, and the necessary further steps to fully develop a holistic Workplace Management theory. 
Table 20.1 Theories in the book presented in alphabetical order

Alignment theory
Branding theory
CREM maturity model
Decision-making theories
Hospitality theory
Principal-agent theory
Radical innovation theory
Resilience theory
Service management theory
Socialization theory
Socio-technical transitions
St. Gallen Management Model
Strategy-as-Practice theory
Systems thinking
Toyota Production System
Usability theory
User-centred design thinking
Value Adding Management model

\section{Concept mapping approach}

To reveal the hidden pattern behind the 19 theories, concept mapping (Kane \& Trochim, 2007) was applied, also known as group concept mapping to distinguish it from mind mapping techniques, such as Novakian concept mapping (Kane \& Rosas, 2018). The concept mapping approach was also used in the first volume of this book series to create an Employee-Workplace Alignment framework (Appel-Meulenbroek et al., 2021). The development process of the said framework and the framework introduced in this chapter has been identical.

Concept mapping is a machine-driven content analysis method that aggregates and integrates knowledge, creating a structure of ideas, values, or opinions. Having evolved from educational planning and evaluation, it now has been used all over the world in a high diversity of disciplines (Trochim, 2017) for purposes such as text analysis, defining priorities, and developing theoretical frameworks (Kane \& Rosas, 2018).

Group concept mapping is a mixed-method approach to extracting knowledge that resides among a group of individuals, the 'wisdom of the crowd'. Technically, the concept mapping process is a combination of brainstorming, card sorting (possibly accompanied by rating), statistical analysis, and data visualisation (Figure 20.1). Rosas and Kane (2012) showed that the method yields strong internal representational validity and very strong sorting reliability estimates.

Since the quested group wisdom was residing in the minds of the book chapter authors living all over the world, the data collection had to be done online. The concept mapping process was led by the research team, consisting of this framework chapter's authors.

\subsection{Unit creation by book chapter authors}

The first step of the concept mapping procedure included the creation of units that could refer to possible communalities and differences between the theories. To keep the balance between the method's reliability and the sorters' burden, the aim was a maximum of around 100 units, as suggested by Kane and Rosas (2018). The authors of this volume have been requested by 

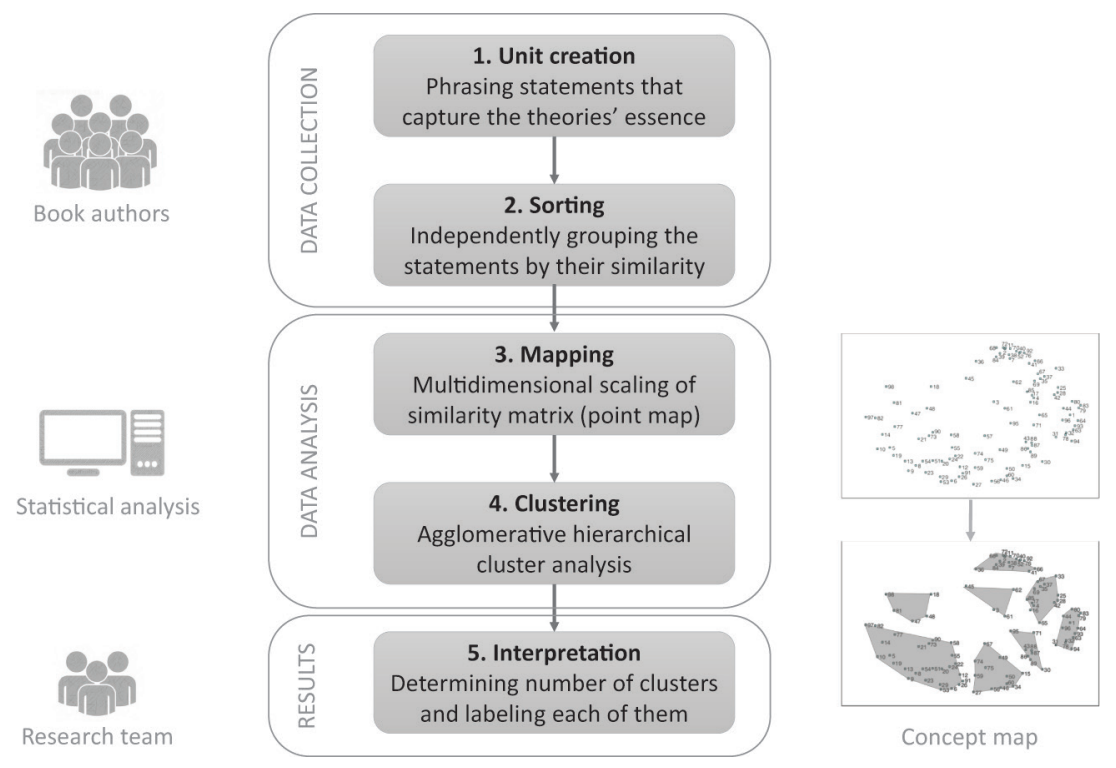

Figure 20.1 Applied concept mapping procedure taking five steps, involving human judgement and computer analysis

email to grasp the essence of their chapter's theory into three to five statements, meeting the following criteria:

- describing essential characteristics or assumptions of the theory, capturing its essential phenomena and relationships,

- making theoretical statements, not phrasing recommendations that follow from the theory, or empirical results,

- containing a maximum of 15 words each (virtually fitting on a Post-it),

- $\quad$ easy to understand for authors from other disciplines,

- clear and comprehensible on its own, even when it is placed between statements about other theories,

- avoiding the theory's name if possible, to reduce recognition of the statement sets.

To further clarify the criteria, the authors were told that the statements "could be, for instance, a definition of the main phenomena, their composition or mutual relationships, the main propositions, assumptions, or values related to the theory, or anything else essential for the theory".

For all the theories, the statements were initially created by the chapter authors. The statements then were discussed between the chapter authors and the three members from the concept mapping research team, until they were clear. The members of the research team individually tested the collected statements by their fit with the aforementioned criteria, discussing the results together. Statements were rephrased if needed to increase their comprehensibility, and similar statements within one theory were deleted. There was no aim for an equal number of statements per theory, since one theory naturally might have more facets than the other. Changes to the original statements were presented to the chapters' authors for approval. In the end a total of 88 units, ranging between three and seven (average $=4.6$ ) statements per theory, was created and stored in an Excel file. 


\subsection{Grouping the statements}

First, the statements were randomised by sorting them alphabetically, after which they were numbered to create the ability to reconnect them to their theory after the sorting. The numbered statements were entered into the remote card sort tool of UsabiliTEST, a Texas-based company providing tools for testing usability and improving information architecture, used by companies and universities worldwide. With this online software, a user test was created for open-ended card sorting, allowing participants to create their own groups according to their logic instead of providing categories beforehand in a closed sort. An open sort is ideal for collecting user-generated ideas for logical content groupings.

The authors were invited to participate in sorting the statements, by sending them an email containing a link to the card sort test which they could not share with others. They were instructed to arrange the cards into groups that made the most sense to them, and that they could create as many groups as they wanted, as long as they did not make a miscellaneous group such as a category 'other' or 'mixed'. They were able to pause the sorting and to continue at a later moment before submitting their contribution to the database. Two weeks before closing the test, a reminder was sent to those who did not yet submit a contribution. To each participant the cards were randomly presented by the system. While authors might still recognise their own statements, tending to put them together, this effect was mitigated by the other sorters' grouping.

A number of at least 11 sorters is required for reliable results, and while having more sorters is better, their added value decreases beyond 20 (Rosas \& Kane, 2012). When the card sort test was closed, eight weeks after the invitation was sent, 19 authors had participated in the sorting with an average completion rate of between $90 \%$ and $100 \%$ of the statements. Sorters would have been excluded from the data analysis if their completion rate was below $20 \%$ or if they had created fewer than three groups, as this would not contribute much to the discriminant validity of the concept mapping. One contribution was excluded based on a low completion rate. On average, the included sorters created 10.5 content groups with a mean of 8 statements per group.

\subsection{Statistical analysis and concept map generation}

First, the raw data from the included sorters were exported from the UsabiliTEST system as an Excel file containing all groups that were created by the sorters and the names they had given them. These data were cleaned by deleting three miscellaneous groups (labelled, e.g., 'temporary group' or 'cannot place these'), since these statements were not grouped based on content similarity and therefore including these groups would distort the analysis. On this cleaned file R-CMap (Bar \& Mentch, 2017) was run, a piece of open-source software in R programming language. The first step of the analysis involved mapping (see Figure 20.1, step 3), using nonmetric multidimensional scaling to transform the multidimensional data into a two-dimensional representation of the relative distances between the statements. This resulted in a point map, where each point represented a statement and the distance between them represented their content difference (the closer, the more similar). The second step (Figure 20.1, step 4) involved agglomerative hierarchical clustering, subsequently merging the two clusters at shortest distance, determined by the closest pair of points.

Since there was no desired number of clusters to aim for, the dendrogram was viewed to indicate the useful range of cluster amounts to consider. In this tree representation of the Ward clustering process, the length of stems represented the distance between two merged clusters while corresponding to the within-cluster variance. Based on the dendrogram, the cluster analysis iterations ranging from 4 to 11 clusters were studied closely by each member of the research 
team to decide at what point the next merging was not logical or did not contribute to clarity of the themes. This resulted in the preference for nine clusters.

\section{Results}

\subsection{Identified clusters and labels}

The concept mapping revealed a nine-themed structure underlying the 19 theories (see Figure 20.2). Closer points or clusters on the map signal more similarity. Nonetheless, there might be some discrepancies due to translation to two dimensions for the map. Cluster names were chosen by the research team, based on the statements' content and inspired by group labels that were created by the sorters. Statements in the centre of the cluster were considered of greater weight in the decision process, and distances to other clusters were also taken into account.

Additionally, Figure 20.2 shows the three-cluster solution of analysis, by the lines drawn around the clusters. This shows three main regions of meaning that this Workplace Management framework beholds:

- creating a resilient organisation,

- aligning organisation and workplace strategies,

- creating positive workplace experience.

\subsubsection{Creating a resilient organisation}

The first two clusters together form the region of meaning called 'Creating a resilient organisation'. This region of meaning focuses on an organisation's ability to anticipate change and

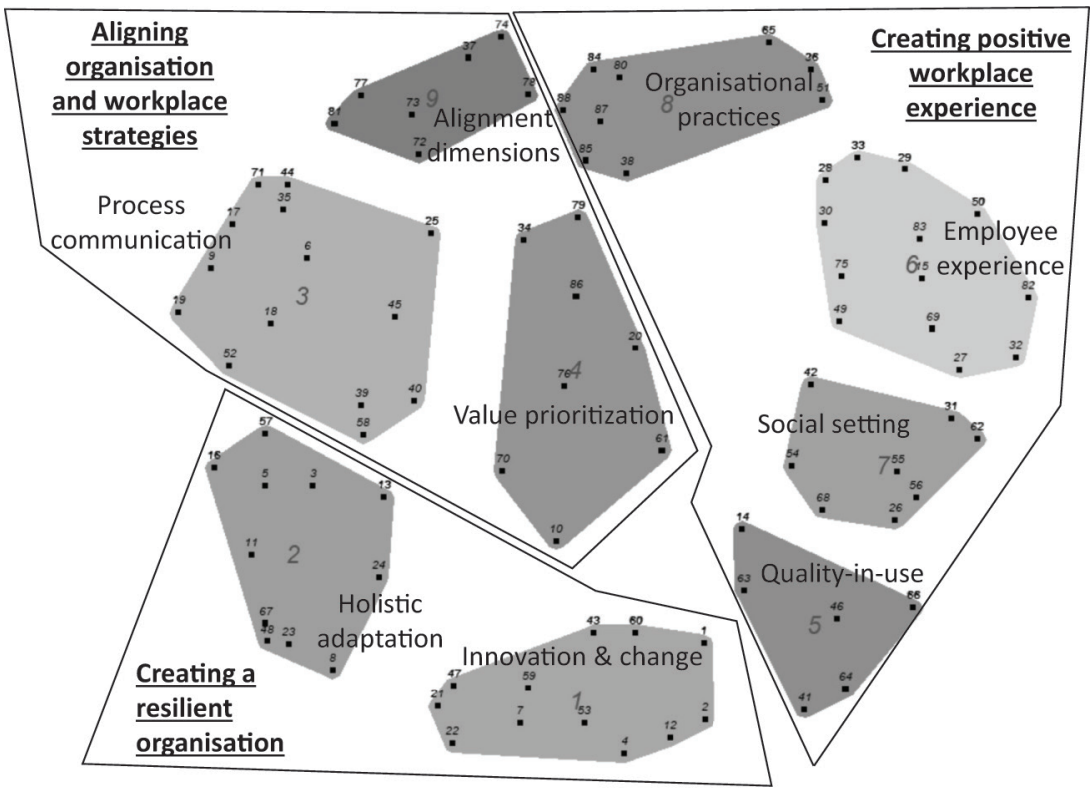

Figure 20.2 Concept map showing clustering of the 88 statements into nine concepts and three regions of meaning 
innovate, in order to maintain or even improve organisational performance over time. Such an ability to change and adapt requires strategic decision-making and a holistic view of the organisation and its workplaces.

Cluster one, labelled 'Innovation \& change', discusses how different-scale internal and external changes impact the workplace. The 12 statements that form the cluster point out that there are various big and small changes that affect a workplace at different levels and in different time frames, putting technology forward as an important example. These changes impact the prevailing workplace (design) and also organisational performance related to it. The statements also point out that taking a performance-based approach to buildings promotes innovation in both workplace design and construction. Statement 7 summarizes the cluster nicely by saying that "Both external and internal changes impact workplace (design) at different scales, tempos, and magnitudes". Other example statements are: "Technology innovations can transform a workplace by enriching, integrating, expanding or inspiring" (statement 59) and "The differing permanency of building layers allows changes to workplace design in different time frames" (statement 60).

The cluster 'Holistic adaptation' (cluster 2) describes the need to have a holistic approach to change management. Two central statements summarise this cluster well: "Changes in one level of the organisation lead to changes on the other level of the organisation" (statement 11) and "Adding value is a holistic, multi-dimensional and transdisciplinary concept" (statement 5). The organisational system is interconnected and thus requires a holistic coordination. The focus of workplace management should be directed at decision support processes towards common values, objectives, and incentives, to reduce problems that might arise and to help add value to the organisation. Moreover, strategic coordination should be resilient in time. Other example statements of this cluster are "A good strategy includes flexibility criteria for future adaptations" (statement 3), "Risk reduction strategies and plans require a longitudinal view of vulnerability and resilience" (statement 48), and "Strategic outputs of workplace projects depend on effective coordination of interactions between workplace (system) components" (statement 57).

\subsubsection{Aligning organisation and workplace strategies}

The second region of meaning shows that one of the key activities of workplace management should be achieving alignment between the organisation and the workplace. It emphasises the strategic role of workplace management in the organisation and encompasses both the structure and process of alignment, plus its complexity. It contains three different clusters with 29 statements stemming from the largest number of theories.

The cluster labelled 'Process communication' (cluster 3) consists of 14 statements that indicate that the alignment process requires two-way integration, both vertically and horizontally, throughout the organisation. Alignment between various units of the organisation means that various problems can arise from conflicting interests between stakeholders, governance issues, or lack of trust. However, a suitable process and enhanced communication has the potential to reduce these problems. After all, social interactions also drive organisational strategy. Example statements of this cluster are "Corporate strategy and workplace strategy require two-way integration" (statement 18), "Problems can be simplified by attributing uncertainties and creating a set of alternatives" (statement 45), and "Potential problems between business and CRE units could be reduced through information sharing, co-creation and alignment" (statement 44).

Cluster 9, 'Alignment dimensions', includes seven statements. They explain the alignment components and processes that are necessary for a successful alignment between the organisation and its workplace. The statements show that workplace alignment involves different 
components such as alignment between physical space, ICT, people, processes, and culture on different organisational levels. Workplace alignment is also an iterative process of repetitive analyses that involves multiple stakeholders and requires addressing multiple perspectives. Workplace interventions thus need to be strategically aligned to the organisation's goals to ensure they add value before they are implemented. Example statements are "Workplace alignment should occur on different organisational levels" (statement 73) and "Workplace alignment is complex and iterative" (statement 72).

Cluster 4, 'Value prioritization' emphasizes the value generation for the stakeholders. The eight statements comprising this cluster continue to open up the complexity of workplace management and show the need to tailor its tasks to the specific context and desired values of an organisation. Workplace management activities can add value to multiple stakeholders through different activities, which should thus be evaluated based on multiple aspects. Example statements include "Workplace management demands understanding of multiple objects, directions and values" (statement 79), "Workspace management means mastering complexity to sustainably generate value for stakeholders" (statement 86), and "Values can be prioritized depending on urgency, importance, cost, impact, and enhancing or hindering conditions" (statement 70).

\subsubsection{Creating workplace experience}

The third region of meaning, 'Creating workplace experience', is the most extensive one, including 35 statements. Four clusters form this region of meaning and emphasise workplace management practices and the need to create a positive employee experience, to provide a suitable social setting, and to ensure perceived quality-in-use. This region of meaning promotes a humanistic perspective on organisations and workplace management, emphasising the vital role of all kinds of employees to the success of the organisation.

The 'Organisational practices' cluster (cluster 8) includes nine statements that point out the role of the workplace as an organisation's service to employees, and the necessary steps to achieve a positive workplace experience for all. The cluster emphasizes that workplace management requires an understanding of the organisational and management practices that govern all kinds of human behaviours. Workplace management processes should analyse, plan, implement, and optimise both business and support processes by taking a close look at practices of the main stakeholders. Example statements of this cluster are "Workplace management strategies can be improved by 'systems-thinking' and mapping stakeholders' interests, barriers and priorities" (statement 80), "It's not the service, it's not the needs, it's the way you deliver the service" (statement 36), and "Service-oriented management emphasizes the relationship between human behaviour and organisational practices" (statement 51 ).

Cluster 6, 'Employee experience', is formed from 13 statements that concentrate on the workplace experience of the end user: an organisation's employees. A positive employee experience is created by enabling them to perform the necessary tasks in an efficient and pleasant way. However, their overall experience depends on multiple tangible and intangible, internal and external factors and their own preferences and personality. All these factors need to be addressed together. Example statements are "User experience should be the primary concern of workplace design and management" (statement 69), "Workplaces should allow the user to execute a task effectively, efficiently and with satisfaction" (statement 83), and "Consumers prefer a product/service that aligns with their own desired personality" (statement 15).

The 'Social setting' cluster (cluster 7) includes eight statements that demonstrate the importance of organising and empowering specifically the (service providing) employees involved in the workplace management. Social interactions are especially important for new recruits or 
insourced employees. Well-socialised employees can help to preserve organisational culture, affect organisational decision-making and improve customer (user) experience. Example statements include "Socialisation provides new recruits with a set pattern of behaviour to help them blend into the organisation" (statement 55), "Socialised employees tend to have better interactions with customers, which means an improved customer experience" (statement 56), and "Unplanned social interactions in the workplace can influence decision and actions of strategic importance" (statement 68).

The 'Quality-in-use' cluster (cluster 5), combined from five statements, emphasises workplace management operations. The statements in this cluster highlight the usage phase of the building and workplace environment, stating that the value of the physical space lies in how good it eventually is for its users. However, it is also the most resource-intensive phase of the building that requires suitable management to avoid unnecessary waste in the usage of buildings. Example statements are "Quality-in-use is eventually more important than architectural, technical or planning quality" (statement 46), “There must be a balance between output, process and subjective experience of the environment" (statement 66).

\subsection{Relations between theories}

Based on the statements in each cluster, it is possible to detect which theories are represented in that cluster and to what extent (see Table 20.2). The table shows that while some of the theories spread out over multiple clusters, others have more than half of their statements congregated in one cluster (e.g. radical innovation, resilience, user-centred design thinking). These theories might concentrate more heavily on a certain phenomenon or a construct and sometimes might be considered as micro-theories (see Chapter 1 on a discussion on types of theories).

Figure 20.3 provides a visualisation of Table 20.2 of the position of the theories related to the regions of meaning. While some theories cover all three regions of meaning, others are focused on one or two of those. The theory of alignment together with the CREM maturity model specifically focus on the organisation and workplace alignment region. Radical innovation theory, Resilience theory and Socio-technical transitions consider the role of innovation, change, and the time aspect and provide assumptions focused on how to create a resilient organisation. Hospitality, Socialisation and User-centred design thinking open up on the human aspect that plays an important role in creating the overall workplace experience and which might not be covered well in other theories that aim to intersect between the regions of meaning. Two theories (Principal-agent and Decision-making) are located on the intersection between 'Aligning organisation and workplace strategies' and 'Creating a resilient organisation'. This seems logical, as both theories approach the issues related to informed decision-making in organisations. Further, the intersection between 'Aligning organisation and workplace strategies' and 'Creating positive workplace experience' regions of meaning holds the largest amount (five) of the theories, namely Strategy-as-Practice theory, St. Gallen Management Model, Toyota Production System, Usability, and Service management. Indeed, these models and theories consider various aspects of workplaces that need to be addressed in order to create the overall experience, and many of those aspects are related to suitable management practices and alignment of operations in the organisation. Only one theory, Performance-based building, is located on the intersection between 'Creating a resilient organisation' and 'Creating positive workplace experience'. This theory concentrates on the building design that, if built according to the performance requirements, can improve both organisational outcome (resilience of the organisation) and personal outcome (experience). However, as there is only one theory in this intersection, this indicates a gap to be addressed in the further 
Table 20.2 Theories represented in the nine clusters by fewer than half $(\bullet)$, exactly half $(\bullet \bullet)$, or more than half $(\bullet \bullet \bullet)$ of their three to seven statements.

\begin{tabular}{|c|c|c|c|c|c|c|c|c|c|}
\hline & 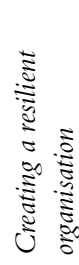 & & 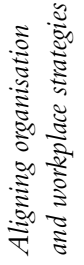 & & & 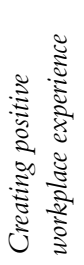 & & & \\
\hline & 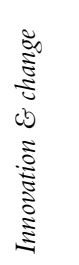 & 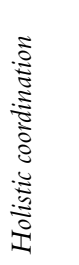 & 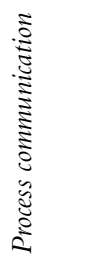 & 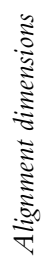 & 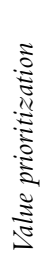 & 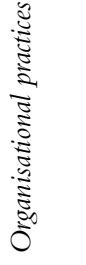 & 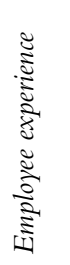 & 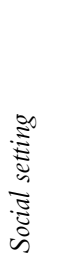 & 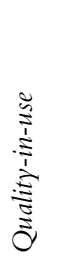 \\
\hline & $\dot{r}$ & $\dot{i}$ & $\dot{n}$ & $a$ & $\dot{\nabla}$ & $\infty$ & 6 & $\sim$ & in \\
\hline Alignment & & & $\bullet$ & $\bullet$ & $\bullet$ & & & & \\
\hline Branding & & $\bullet$ & $\bullet$ & & & & $\bullet$ & $\bullet$ & \\
\hline Decision-making & & $\bullet$ & $\bullet$ & $\bullet \bullet$ & & & & & \\
\hline Hospitality & & & & & & $\bullet$ & $\bullet \bullet \bullet$ & $\bullet$ & \\
\hline CREM maturity model & & & $\bullet \bullet$ & $\bullet$ & $\bullet$ & & & & \\
\hline Performance-based building & $\bullet \bullet \bullet$ & & & & & & & & $\bullet$ \\
\hline Principal-agent & & $\bullet$ & $\bullet \bullet \bullet$ & & & & & & \\
\hline Radical innovation & $\bullet \bullet \bullet$ & & & & & & & & \\
\hline Resilience & & $\bullet \bullet \bullet$ & & & & & & & \\
\hline Strategy-as-Practice & & & $\bullet \bullet \bullet$ & & & & & $\bullet$ & \\
\hline Service management & & & & & $\bullet$ & $\bullet$ & $\bullet$ & & $\bullet$ \\
\hline Socialization & & & & & & & & $\bullet \bullet \bullet$ & \\
\hline St. Gallen Management Model & & & & & $\bullet$ & $\bullet \bullet \bullet$ & & & \\
\hline Socio-technical transitions & $\bullet \bullet \bullet$ & $\bullet$ & & & & & & & \\
\hline Systems thinking & & $\bullet$ & $\bullet$ & $\bullet$ & & $\bullet$ & & & \\
\hline Toyota production system & & & $\bullet$ & & & & & & $\bullet \bullet \bullet$ \\
\hline User-centred design thinking & & & & & & & $\bullet \bullet \bullet$ & & \\
\hline Usability & & & & & $\bullet$ & & $\bullet$ & $\bullet$ & - \\
\hline Value Adding Management & $\bullet$ & $\bullet$ & & $\bullet$ & $\bullet$ & $\bullet$ & & & \\
\hline
\end{tabular}

development of the Workplace Management framework. Lastly, Branding theory, Systems thinking and the Value Adding Management model cover all three regions of meaning and, thus, are placed in the middle of the figure at the intersection of all regions. These theories indeed consider a wide variety of aspects within organisations, management practices, and workplace features, and could thus be considered more of a grand or mid-range theory with broader theoretical perspectives. For example, the Value Adding Management model is a specialised model for facilities and real estate management practices that should be addressed to add value to organisations, emphasising the alignment and flexibility (e.g. resilience) aspects. Overall, all theories seem to be logically placed in the concept mapping process, confirming the validity of the outcome of this method. 


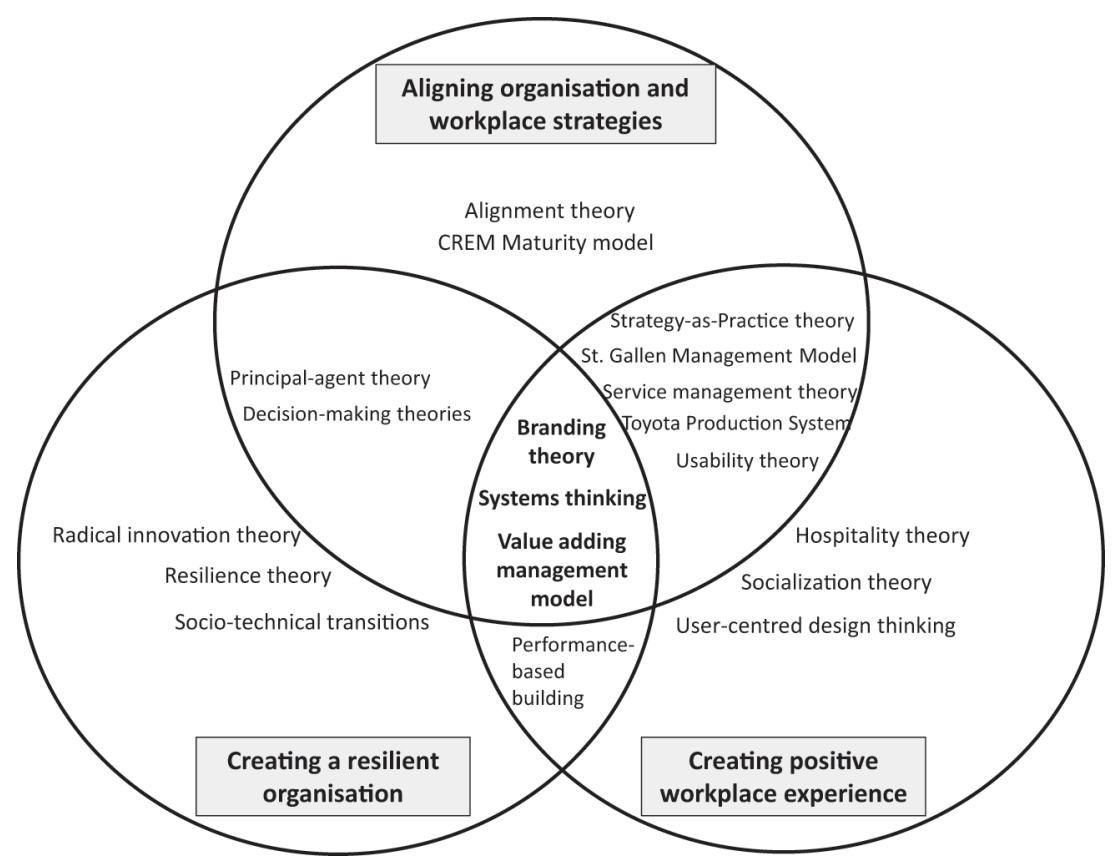

Figure 20.3 Workplace management theories forming three regions of meaning

\section{Discussion}

\subsection{Towards a new grand theory on workplace management}

All three regions of meaning from the cluster analysis discuss the role of workplace management in terms of tasks, processes, strategies, and stakeholders. It should optimise workplace experience for all stakeholders through the creation of a resilient organisation and alignment between organisational needs and the workplace strategy and interventions. Also, by creating a better workplace experience and aligning the workplace to organisational strategies, workplace management can create a more resilient organisation. There should thus be a continuous (change) management process of aligning to both internal and external forces and generating value for all different stakeholders. This chapter now starts its first attempt to develop the framework for a holistic grand theory on workplace management. It takes the nine concepts and three regions of meanings as possible constructs of such a theory. Figure 20.4 visualises their connections using two-directional arrows, as the exact relationships are yet to be determined in further research. This will require more research on the connections between the regions and between the concepts in these regions.

Current fast-pace changes in organisations and markets require a continuous change in workplaces to stay aligned, as visible in the 'Creating a resilient organisation' part of this framework. The workplace is a reflection of organisational culture and 'personality' (e.g. Parker, 2016; Harris, 2015), so it needs to realign following organisational changes over time. The skill to adapt to various changes leads to increased resilience of organisations (Duchek, 2020). In her doctoral thesis, Saurin (2012) analysed possible futures for workplaces and already highlighted the need to address the complexity of workplace management together with uncertainty and a constant change. She states that only by understanding that a workplace is a complex system 


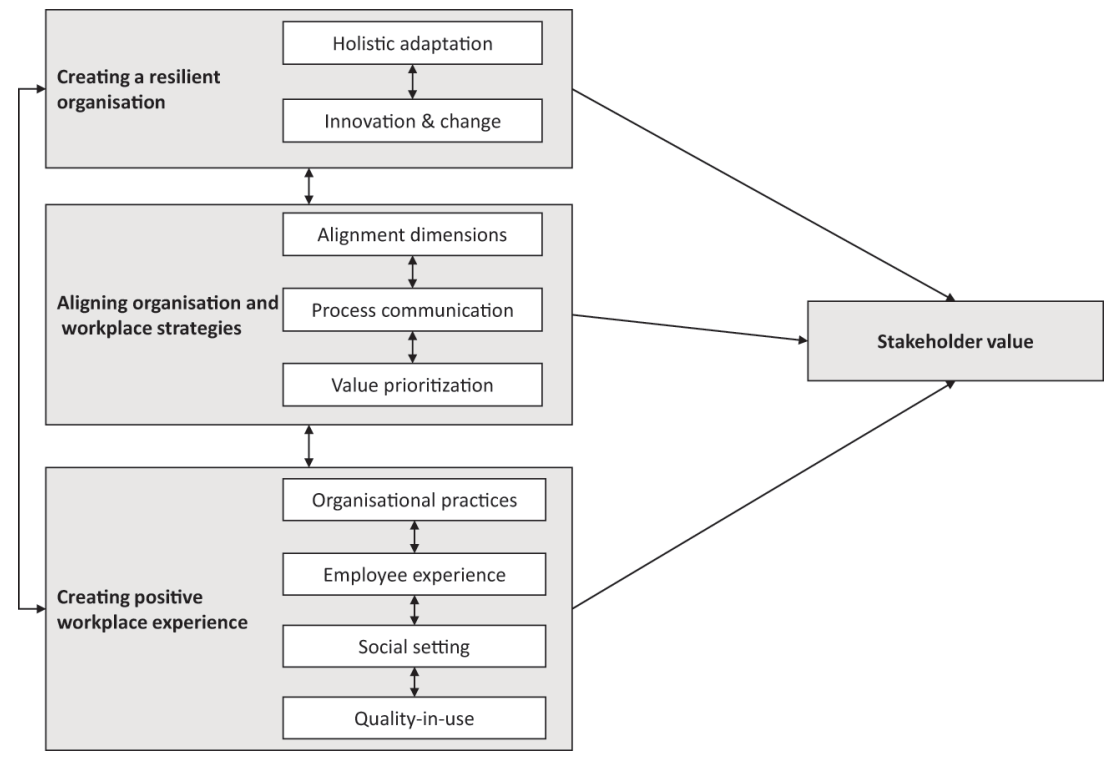

Figure 20.4 Workplace Management framework

that is affected by various forces and interpreted by different individuals, one can successfully prepare for the possible future. However, so far, research on resilience in the workplace appears to either be focused on the organisation itself in times of emergency (e.g. Parsons, 2010), or highly competitive markets (e.g. Borekci et al., 2015), or on resilience of the organisation's employees, referring to keeping them healthy and productive at work (e.g. Robertson et al., 2015). Resilience of workplace-organisation alignment through time is hardly studied. Burnard and Bhamra (2011, p. 5587) defined organisational resilience as:

the emergent property of organisational systems that relates to the inherent and adaptive qualities and capabilities that enable an organisation's adaptive capacity during turbulent periods. The mechanisms of organisational resilience thereby strive to improve an organisation's situational awareness, reduce organisational vulnerabilities to systemic risk environments and restore efficacy following the events of a disruption.

There is no quick fix or single process towards creating resilience, as this is not an outcome but rather a continuous process towards agility (Gibson \& Tarrant, 2010). The few existing studies either address the actual flexibility of the building construction to make (structural) changes (e.g. Geraedts, 2016) or remain very much on a conceptual level (e.g. Gibson, 2001). As Cooke et al. (2019) have identified, CRE portfolios did not yet have the agility for dynamic alignment during the most recent economic recession. The framework thus supports their call for more research on the decision-making process of workplace managers when trying to achieve realignment (Cooke et al., 2021) and why this is not successful.

Organisational resilience also depends on the organisational capabilities to innovate (Mafabi et al., 2015). Organisations need to constantly develop and renew their capabilities (structures, processes, and competences) in order to stay competitive (Hamel \& Välikangas, 2003). As creativity is critical in this innovation process, organisations need creative environments to enhance the creativity in the organisation (Serrat, 2017). Physical space design can influence creativity 
through enhancing or at least not hindering processes and activities in the organisation (Martens, 2011; Vithayathawornwong et al., 2003). Additionally, successful innovation adoption depends on time, the social system, and communication in the innovation decision process (Rogers, 2003). This emphasises the role of change management that needs to consider and address different needs of multiple stakeholders while ensuring a smooth and continuous improvement process, as represented by the 'Process communication' component of the framework. Change management literature shows that employees are critical in the success or failure of change within the organisation. This is due to the fact that they are either the ones that are affected by the change or the ones that implement the change (Fugate et al., 2012). Thus, it is important to make sure that employees are engaged, and that their needs are heard. This can be achieved by involving employees in the change process and addressing their needs (e.g. García-Cabrera \& García-Barba Hernández, 2014; Morin et al., 2016; Skogland \& Hansen, 2017). In short, workplace management should concentrate on the continuous change management process that addresses the change experienced by an organisation to support an organisation's primary processes. However, more research on workplace change management processes is necessary to identify what works in which context and how workplace managers can enhance knowledge creation processes in the organisation to increase flexibility and resilience of the workplace.

The 'Aligning organisation and workplace strategies' part of the framework puts workplace management forward as a complex adaptive system (CAS). Holland (2006, p. 1) defines complex adaptive systems as "systems that have a large number of components, often called agents, that interact and adapt or learn". Main features of a CAS are that it has a high number of agents who make their own decisions on how to behave. Agents are seen as autonomous objects that have local knowledge and can be replaced without disrupting the whole system (Carmichael \& Hadžikadić, 2019). They interact with each other, and the behaviour of the whole system cannot be predicted based on the behaviour of individual agents, thus requiring a holistic understanding of the system (Sullivan, 2011). In addition, agent behaviour changes depending on events taking place. Interactions between agents as well as other internal and external changes thus influence the system's behaviour. Kämpf-Dern and Pfnür (2014) studied corporate real estate management (CREM) as an organisational management function and confirmed that it is a complex system composed of multiple various relationships and interactions. There are internal and external environments as well as inter- and intra-systems that affect CREM (Kämpf-Dern \& Pfnür, 2014) on strategic, tactical, and operational levels. Moreover, within the workplace, there are multiple operational levels - physical space, digital environment, and social environment that interact together. All these components might influence the outcome or actions of other parts. Additionally, workplaces have many stakeholders coming both from internal and external environments, such as employees, management, investors, suppliers, and public bodies (Kämpf-Dern \& Pfnür, 2014). All of them can be referred to as someone who has a relationship with a certain workplace (Tagliaro, 2018) and, thus, can be considered as system agents. In this manner, workplace has a loose hierarchy of replaceable agents.

The stakeholders (agents) that need to be catered by workplace management often have different interests. These interests might be understood as a value that workplace management needs to bring to the organisation (see also Chapter 12 on the Value Adding Management model). The understanding of value has been changing from mere 'cost savings' to broader performance increases in the organisation's core business, such as increased productivity, improved image of the organisation, and increased employee engagement (e.g. Haynes, 2007; KämpfDern \& Konkol, 2017). Nonetheless, De Vries et al. (2008) pointed out that financial performance is still a dominant performance indicator in organisations, and thus many interventions that relate to (physical) workplace are judged through the financial point of view. Concentrating 
solely on minimising real estate costs can hurt organisations more in other parts of the system (De Vries et al., 2008). Finding the most suitable workplace solutions for different stakeholders is one of the major tasks for workplace management to achieve alignment between the organisation and the workplace. This alignment must be understood as a change on a system level which is easier to achieve than at the individual (agent) level (Carmichael \& Hadžikadić, 2019). Corporate real estate and workplace alignment have been widely studied within the CREM field (see Chapter 9 on the alignment models). Heywood and Arkesteijn (2018) also indicated that it is essential to better understand the relationships between the components and the dynamics of decision-making in the organisation. Thus, deeper studies of the relationships between components (agents) and workplace decision-making dynamics are needed.

The 'Creating workplace experience' part of the framework covers factors affecting overall workplace experience. Workplaces are increasingly considered as a product that is consumed by employees (customers). A related term, 'consumption experience', was introduced in the late 20th century. At that time, Holbrook and Hirschman (1982) discussed how experience (customer response) relates to both environmental and consumer factors. They identified that products, their features, and benefits, together with verbal stimulus and non-verbal cues (such as smell, taste, feeling), and communication affect customer response. In order to capture the customer, businesses need to create a memory for their customers (Pine II \& Gilmore, 1998). Both these studies (and many more) point out that experience of consuming any product or service comes not only from the product or service itself, but also from how customers perceive the interactions with business, personnel, and the environment. Grönroos (1984) developed a framework that helps to understand service quality, suggesting that it is specifically perceived by how well the delivered service meets customer expectations. The model separates technical (what a customer gets) and functional (how a customer gets it) quality dimensions, and image (how a customer perceives the provider). Regarding the technical part, workplace experience and satisfaction depend on workplace characteristics such as indoor environmental quality or layout design. There are many studies that analyse which physical workplace factors affect the productivity, satisfaction, and health of employees. Indoor air quality and ventilation, thermal comfort, lighting and daylight, noise and acoustics, office layout, biophilia and views, look and feel, and location and amenities seem to be the common physical environment factors that play a role (Al Horr et al., 2016). Regarding the functional quality (how a customer gets the service experience), the framework shows that in the office workplace, quality also stems from social interactions and organisational practices (see also Chapter 17 on hospitality). This makes employees critical in workplace management success. Multiple studies confirm that employee behaviour affects customers' perceptions of quality and overall satisfaction (e.g. Kattara et al., 2008; Butcher, 2005; Li, 2020). These human behaviours and interactions also relate closely to how workplace characteristics and organisational practices are perceived (the image part of Grönroos's model). Perceived satisfaction with a product or service is widely studied, for example in service management and hospitality management fields. The subjective image of how well the workplace meets an employee's needs strongly determines whether positive employee attitudes and wellbeing are achieved (Edwards \& Shipp, 2007). Only when all three types of service quality are positive, could the workplace, from a physical point of view, be understood as a healthy space that supports productive work. How to achieve more optimal alignment between a workplace and individual employee thriving is discussed in more detail in the first book of this series, addressing another 21 different theories specifically on this topic.

A workplace does not consist only of the physical environment but is also defined by the organisation, the job itself, and personal characteristics (Jensen \& van der Voordt, 2019). Perceived 
productivity, for example, depends on a person's interaction with the workplace as well (Haynes, 2009). Hence, to satisfy the eventual 'real' customer of the organisation, workplace management needs to understand the interactions between organisational practices, employee experience, their social setting, and continuous quality-in-use to create an overall positive workplace experience from aligning a workplace to the organisation. However, the alignment of these dimensions is complex and layered. Even though there is a significant amount of research showing correlations between different dimensions of workplace experience, there are no straightforward answers regarding the relationship between them yet. Hence, more research is needed to understand the causal order of these dimensions and provide more conclusive evidence.

The nine concepts presented in this chapter form the basis for further development of a holistic Workplace Management theory. In general, the concepts indicate that the main tasks of workplace management include alignment of organisational and workplace strategies and creating a resilient organisation and positive workplace experience. This emphasises the need of workplace management to address both organisational practices and human needs on operational, tactical, and strategic levels of the organisation in order to create value for all stakeholders. Often, difficulties appear when the workplace is understood as a physical space or organisational (social) setting only. This framework sees workplace as a combination of physical, social, and mental space. Physical and social space comes forward in several clusters of the framework, and mental space could be understood as the overall employee experience of the workplace. Thus, referring back to Tissen and Lekanne Deprez (2008), workplace management indeed can be seen as that complex system of physical, social, and mental space within (and outside) organisational borders.

\subsection{Limitations and future steps}

One of the main limitations of the framework in this chapter is that it is based on 19 theories that were selected in an uncontrolled manner. These theories emerged from suggestions within the editors' networks. Thus, the first future step for further development of this framework is to verify whether the identified concepts cover all necessary aspects of a holistic Workplace Management theory. Also, the assumptions extracted from these theories that were used for the concept mapping study could be different if authors from other disciplines would have created them. Furthermore, the interpretation of the assumptions could be different if they would be analysed and sorted by scholars other than the authors of this book. To diminish these limitations, the concepts presented in this framework could be discussed with a group of representatives from different academic fields as well as workplace managers in practice.

In order to develop the theory further, it would be necessary to test or continue testing relationships between the nine identified concepts, as right now we cannot indicate the directions of relationships in the framework. In the discussion, many research gaps have been identified. Figure 20.3 provides insights in which theories could be used for further research if researchers would like to develop specific concepts or understand certain interactions better. As the framework incorporates multiple dimensions, it might be difficult to study all the aspects together (Giddens, 1979); however, a holistic understanding is also needed. Additionally, in order to connect research on the different dimensions, a common scale for testing relations would be helpful too. Currently in workplace management research, the scales vary depending on the study. A common measurement scale would require a complex process (Carpenter, 2018) that has not yet been done either, but that would be worth the effort. After these steps have been implemented, further data collection and empirical testing in different settings would be necessary to specify the conditions under which the Workplace Management theory holds. 
Only then could the framework that is presented in this chapter be developed towards a proper grand Workplace Management theory.

\section{Implications for practice}

This chapter develops workplace management research further, thus, it is oriented mostly towards researchers. However, workplace managers in practice can find the chapter helpful too, by looking at how they address the different aspects in the framework. First, the 'Creating a resilient organisation' part discusses the role of change and innovation in a successful business and the need for constant adaptation of a physical workplace to stay aligned. Still, too often physical workplace transformation is seen as a one-time project with a definite beginning and end, after which only efficient management of operations is needed. Achieving resilience and agility requires a more continuous approach towards the development of workplace management structures, processes, designs, and competences, including the focus on workplace support of both the organisational processes (such as knowledge sharing) and employees as individuals, while creating a social system around the physical (and digital) space.

Also, the 'Aligning organisational and workplace strategies' part is relevant to practitioners. It emphasises the need for workplace management strategy and actions to be aligned to a specific organisation, with its own complex system and unique set of multiple specific stakeholders that workplace managers need to address. Alignment and changes in the workplace should be well communicated with the relevant stakeholders, especially not forgetting the users of the space (employees). Although practitioners are adopting user-centred design thinking and increasingly involve some users early on in the workplace development process, real participatory design with all users has not been adopted by many organisations yet.

Last, the 'Creating positive workplace experience' part is also beneficial to practitioners and it might be the least understood part, due to the fact that it emphasises human behaviour and psychology factors. Often workplace managers are educated in engineering or management fields without acquiring knowledge from the psychology, sociology, or similar human-centred disciplines. It is common that workplace management is left to practitioners stemming from a technical building management side. As a positive workplace experience is not just because of a high-quality physical space, they must learn how to deal with the social context and individual (physical, functional, and psychological) needs. This indicates that workplace managers need to work more closely with HRM and other employee-focused departments, so that employee needs can be addressed together to create a holistic positive workplace experience. Also, workplace managers can incorporate knowledge from the hospitality sector on designing experiences and adjusting their organisational practices to increased service quality.

\section{Closing words}

Managing office buildings started with only the operational management of physical space, then moved towards managing offices as a financial asset, and now finally includes the recognition that offices can affect user behaviour. Thus, workplace is no longer seen as a pure cost centre but as a value-adding asset of an organisation. Nonetheless, many organisations still do not understand how workplace management should be performed in practice and underestimate the need to connect with other support functions (FM, HR, IT), to align to organisational strategies and capture the full value that workplaces can bring to organisations and their stakeholders. Supporting employees and enabling appropriate work practices can bring more than cost savings on energy or square metres. Often, behavioural and psychosocial outcomes are 
missed out in workplace management performance ratings, forgetting that people perceive the environment around themselves and create impressions about the workplace and the organisation that strongly influence their functioning on the job (for both the 'regular' employee and the workplace management team itself). Thus, perhaps we should move beyond discussion on terms as corporate real estate and facilities management towards the more human-focused workplace management term. Hopefully, the Transdisciplinary Workplace Research and Management book series will continue, and new books will present even more theories that are (or can be) applied to further advance the workplace management field.

\section{References}

Alexander, K., \& Price, I. (2012). Managing Organizational Ecologies: Space, Management, and Organizations. New York, NY: Routledge.

Al Horr, Y., Arif, M., Kaushik, A., Mazroei, A., Katafygiotou, M., \& Elsarrag, E. (2016). Occupant productivity and office indoor environment quality: A review of the literature. Building and Environment, 105, 369-389. doi:10.1016/j.buildenv.2016.06.001

Appel-Meulenbroek, R., Colenberg, S., \& Danivska, V. (2021). Towards an interdisciplinary employeeworkplace alignment theory. In R. Appel-Meulenbroek \& V. Danivska (Eds.), A Handbook of Theories on Designing Alignment Between People and the Office Environment. New York, NY: Routledge.

Bar, H., \& Mentch, L. (2017). R-CMap: An open-source software for concept mapping. Evaluation and Program Planning, 60, 284-292. doi:10.1016/j.evalprogplan.2016.08.018

Becker, F. D. (1981). Workspace: Creating Environments in Organizations. New York, NY: Praeger.

Blakstad, S. H., Hansen, G. K., \& Knudsen, W. (2008). Methods and tools for evaluation of usability of buildings. In K. Alexander (Ed.), Usability of Workplaces - Phase 2. www.irbnet.de/daten/iconda/ CIB8905.pdf

Borekci, D. Y., Rofcanin, Y., \& Gürbüz, H. (2015). Organisational resilience and relational dynamics in triadic networks: A multiple case analysis. International Journal of Production Research, 53(22), 6839-6867. doi:10.1080/00207543.2014.903346

Burnard, K., \& Bhamra, R. (2011). Organisational resilience: Development of a conceptual framework for organisational responses. International Journal of Production Research, 49(18), 5581-5599. doi:10.1080/ 00207543.2011 .563827

Butcher, K. (2005). Differential impact of social influence in the hospitality encounter. International Journal of Contemporary Hospitality Management, 17(2), 125-135. doi:10.1108/09596110510582323

Carmichael, T., \& Hadžikadić, M. (2019). The fundamentals of complex adaptive systems. In T. Carmichael, A. Collins \& M. Hadžikadić (Eds.), Complex Adaptive Systems. Understanding Complex Systems. Cham: Springer. doi:10.1007/978-3-030-20309-2_1

Carpenter, S. (2018). Ten steps in scale development and reporting: A guide for researchers. Communication Methods and Measures, 12(1), 25-44. doi:10.1080/19312458.2017.1396583

Coenen, C., Alexander, K., \& Kok, H. (2013). Facility management value dimensions from a demand perspective. Journal of Facilities Management, 11(4), 339-353. doi:10.1108/JFM-10-2012-0049

Cooke, H., Appel-Meulenbroek, R., \& Arentze, T. (2019). Adjustment of corporate real estate during a period of significant business change. International Journal of Strategic Property Management, 23(3), 171-186. doi:10.3846/ijspm.2019.7954

Cooke, H., Appel-Meulenbroek, R., \& Arentze, T. (2021). Lifting the lid on the black box of corporate real estate decision making; dealing with surplus property. Journal of European Real Estate Research, online first. doi:10.1108/JERER-05-2020-0029

Corley, K. G., \& Gioia, D. A. (2011). Building theory about theory building: What constitutes a theoretical contribution? Academy of Management Review, 36(1), 12-32. doi:10.5465/amr.2009.0486

De Vries, J. C., de Jonge, H., \& van der Voordt, T. J. M. (2008). Impact of real estate interventions on organisational performance. Journal of Corporate Real Estate, 10(3), 208-223. doi:10.1108/14630010810922094

Duchek, S. (2020). Organizational resilience: A capability-based conceptualization. Business Research, 13 , 215-246. doi:10.1007/s40685-019-0085-7

Edwards, J. R., \& Shipp, A. J. (2007). The relationship between person-environment fit and outcomes: An integrative theoretical framework. In C. Ostroff \& T. A. Judge (Eds.), Perspectives on Organizational Fit (pp. 209-258). San Francisco, CA: Jossey-Bass. 
Fugate, M., Prussia, G. E., \& Kinicki, A. J. (2012). Managing employee withdrawal during organizational change: The role of threat appraisal. Journal of Management, 38(3), 890-914. doi:10.1177/014920 6309352881

Gagné, M. (2018). From strategy to action: Transforming organizational goals into organizational behavior. International Journal of Management Reviews, 20, 83-104. doi:10.1111/ijmr.12159

Galbraith, J. R. (2014). Designing Organizations: Strategy, Structure, and Process at the Business Unit and Enterprise Levels (3rd ed.). San Francisco, CA: Jossey-Bass.

García-Cabrera, A. M., \& García-Barba Hernández, F. (2014). Differentiating the three components of resistance to change: The moderating effect of organization-based self-esteem on the employee involvementresistance relation. Human Resource Development Quarterly, 25, 441-469. doi:10.1002/hrdq.21193

Geraedts, R. (2016). FLEX 4.0, a practical instrument to assess the adaptive capacity of buildings. Energy Procedia, 96, 568-579. www.sciencedirect.com/science/article/pii/S187661021630741X/pdf?md5= 3b45497e117d4c51487bf28d3a7bc3ff\&pid=1-s2.0-S187661021630741X-main.pdf

Gibson, C. A., \& Tarrant, M. (2010). A 'conceptual models' approach to organisational resilience. Australian Journal of Emergency Management, 25(2), 8-14. https://ajem.infoservices.com.au/items/AJEM-25-02-03

Gibson, V. (2001). In search of flexibility in corporate real estate portfolios. Journal of Corporate Real Estate, 3(1), 38-45. doi:10.1108/14630010110811472

Giddens, A. (1979). Central Problems in Social Theory: Action, Structure, and Contradiction in Social Analysis. Berkeley, CA: University of California Press.

Grönroos, C. (1984). A service quality model and its marketing implications. European Journal of Marketing, 18(4), 36-44. doi:10.1108/EUM0000000004784

Hamel, G., \& Välikangas, L. (2003). The quest for resilience. Harvard Business Review. https://hbr.org/ 2003/09/the-quest-for-resilience

Harris, R. (2015). The changing nature of the workplace and the future of office space. Journal of Property Investment \& Finance, 33(5), 424-435. doi:10.1108/JPIF-05-2015-0029

Haynes, B. P. (2007). Office productivity: A shift from cost reduction to human contribution. Facilities, 25(11/12), 452-462. doi:10.1108/02632770710822562

Haynes, B. P. (2009). Research design for the measurement of perceived office productivity. Intelligent Buildings International, 1(3), 169-183. doi:10.3763/inbi.2009.0014

Heywood, C., \& Arkesteijn, M. (2017). Alignment and theory in corporate real estate alignment models. International Journal of Strategic Property Management, 21(2), 144-158. doi:10.3846/1648715X.2016. 1255274

Heywood, C., \& Arkesteijn, M. (2018). Analysing fourteen graphical representations of corporate real estate alignment models. Journal of Corporate Real Estate, 20(1), 16-40. doi:10.1108/JCRE-02-2017-0005

Holbrook, M. B., \& Hirschman, E. C. (1982). The experiential aspects of consumption: Consumer fantasies, feelings, and fun. Journal of Consumer Research, 9(2), 132-140. www.jstor.org/stable/2489122

Holland, J. (2006). Studying complex adaptive systems. Journal of Systems Science \& Complexity, 19, 1-8. doi:10.1007/s11424-006-0001-z

Huselid, M. A., \& Becker, B. E. (1997). The impact high performance work systems, implementation effectiveness, and alignment with strategy on shareholder wealth. Proceedings, 144-148. doi:10.5465/ ambpp.1997.4981101

Jensen, P. A., \& van der Voordt, T. J. M. (2019). Healthy workplaces: What we know and what else we need to know. Journal of Corporate Real Estate, 22(2), 95-112. doi:10.1108/JCRE-11-2018-0045

Kämpf-Dern, A., \& Konkol, J. (2017). Performance-oriented office environments - framework for effective workspace design and the accompanying change processes. Journal of Corporate Real Estate, 19(4), 208-238. doi:10.1108/JCRE-03-2017-0009

Kämpf-Dern, A., \& Pfnür A. (2014). Best practice, best model, best fit. Strategic configurations for the institutionalization of corporate real estate management in Europe. Journal of Corporate Real Estate, 16(2), 97-125. doi:10.1108/JCRE-09-2013-0027

Kane, M., \& Rosas, S. (2018). Conversations about Group Concept Mapping. Applications, Examples, and Enhancements. Thousand Oaks, CA: SAGE.

Kane, M., \& Trochim, W. M. K. (2007). Concept Mapping for Planning and Evaluation. California: ProQuest Sage.

Kattara, H. S., Weheba, D., \& El-Said, O. A. (2008). The impact of employee behaviour on customers' service quality perceptions and overall satisfaction. Tourism and Hospitality Research, 8(4), 309-323. doi: $10.1057 /$ thr.2008.35

Li, J. (2020). Understanding the Perceived Service Quality by Residents in Assisted Living Facilities: A Qualitative Inquiry (Electronic thesis). https://etd.ohiolink.edu/ 
Luhman, J., \& Cunliffe, A. (2013). Organizational space. In Key Concepts in Organization Theory (pp. 135140). SAGE Publications Ltd. doi:10.4135/9781473914643.n26

Mafabi, S., Munene, J. C., \& Ahiauzu, A. (2015). Creative climate and organisational resilience: The mediating role of innovation. International Journal of Organizational Analysis, 23(4), 564-587. doi:10.1108/ IJOA-07-2012-0596

Martens, Y. (2011). Creative workplace: Instrumental and symbolic support for creativity. Facilities, 29(1/2), 63-79. doi:10.1108/02632771111101331

Morin, A. J., Meyer, J. P., Bélanger, É., Boudrias, J.-S., Gagné, M., \& Parker, P. D. (2016). Longitudinal associations between employees' beliefs about the quality of the change management process, affective commitment to change and psychological empowerment. Human Relations, 69(3), 839-867. doi:10.1177/0018726715602046

Parker, L. D. (2016). From scientific to activity based office management: A mirage of change. Journal of Accounting \& Organizational Change, 12(2), 177-202. doi:10.1108/JAOC-01-2015-0007

Parsons, D. (2010). Organisational resilience. Australian Journal of Emergency Management, The, 25(2), 18-20. https://search.informit.com.au/documentSummary;dn=084557405183732;res=IELAPA

Pine II, B. J., \& Gilmore, J. H. (1998). Welcome to the experience economy. Harvard Business Review, 78(1), 97-105. Welcome to the Experience Economy (hbr.org).

Robertson, I. T., Cooper, C. L., Sarkar, M., \& Curran, T. (2015). Resilience training in the workplace from 2003 to 2014: A systematic review. Journal of Occupational and Organizational Psychology, 88, 533562. doi:10.1111/joop. 12120

Rogers, E. (2003). Diffusion of Innovations (5th ed.). New York, NY: The Free Press.

Rosas, S. R., \& Kane, M. (2012). Quality and rigor of the concept mapping methodology: A pooled study analysis. Evaluation and Program Planning, 35(2), 236-245. doi:10.1016/j.evalprogplan.2011.10.003

Saurin, R. (2012). Workplace Futures: A Case Study of an Adaptive Scenarios Approach to Establish Strategies for Tomorrow's Workplace (Doctoral dissertation). https://arrow.tudublin.ie/builtdoc/10/

Serrat, O. (2017). Harnessing creativity and innovation in the workplace. In Knowledge Solutions. Singapore: Springer. doi:10.1007/978-981-10-0983-9_102

Skogland, M. A. C., \& Hansen, G. K. (2017). Change your space, change your culture: Exploring spatial change management strategies. Journal of Corporate Real Estate, 19(2), 95-110. doi:10.1108/ JCRE-07-2016-0024

Steele, F. I. (1973). Physical Settings and Organization Development. Reading, MA: Addison-Wesley Pub. Co.

Sullivan, T. (2011). Embracing complexity. Harvard Business Review. https://hbr.org/2011/09/embracingcomplexity

Tagliaro, C. (2018). A Place for the Workplace to Work. A System of Performance Indicators for Strategic Design, Management and Use of the Workplace (Doctoral dissertation). www.politesi.polimi.it/bitstream/10589/ 142109/3/180907_Thesis_TAGLIARO_PDF_upload.pdf

Tissen, R., \& Lekanne Deprez, F. (2008). Towards a Spatial Theory of Organizations: Creating New Organizational Forms to Improve Business Performance. Nyenrode Research Papers Series 08-04, Nyenrode Business Universiteit. https://prod.surfsharekit.nl/publiek/nyenrode/d367a6ca-7d2f-4bf5-9e65-b0b88e073583

Trochim, W. M. (2017). Hindsight is 20/20: Reflections on the evolution of concept mapping. Evaluation and Program Planning, 60, 176-185. doi:10.1016/j.evalprogplan.2016.08.009

Vithayathawornwong, S., Danko, S., \& Tolbert, P. (2003). The role of the physical environment in supporting organizational creativity. Journal of Interior Design, 29, 1-16. doi:10.1111/j.1939-1668.2003. tb00381.x 